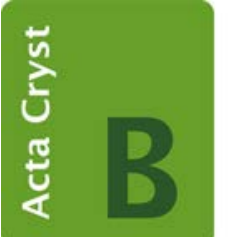

\title{
STRUCTURAL SCIENCE
}

CRYSTAL ENGINEERING

MATERIALS

Volume 75 (2019)

Supporting information for article:

Influence of ligand positional isomerism on the molecular and supramolecular structures of cobalt(II)-phenylimidazole complexes Vasilios Duros, Constantina Papatriantafyllopoulou, Alexandros A. Kitos, Anastasios J. Tasiopoulos and Vassilios Nastopoulos 
Table S1 $\pi \cdots \pi$ stacking distances $(\AA)$ and angles $\left({ }^{\circ}\right)$ in complexes 1-8.

\begin{tabular}{|c|c|c|c|c|c|}
\hline Structure & $\begin{array}{l}\text { Rings } \\
\text { involved* }\end{array}$ & $\begin{array}{l}\text { Distance between } \\
\text { ring centroids }\end{array}$ & $\begin{array}{l}\text { Perpendicular distance } \\
\text { between ring planes }\end{array}$ & $\begin{array}{l}\text { Centroid } \\
\text { offset }\end{array}$ & $\begin{array}{l}\text { Dihedral angle between } \\
\text { ring mean-planes }\end{array}$ \\
\hline \multirow[t]{2}{*}{1} & C1-B2 & $3.715(3)$ & 3.699(3) & $0.347(9)$ & $8.4(2)$ \\
\hline & $\mathrm{D} 2-\mathrm{A} 2^{\mathrm{i}}$ & $3.720(2)$ & $3.423(3)$ & $1.448(6)$ & $4.9(1)$ \\
\hline \multirow[t]{2}{*}{2} & $\mathrm{~A} 2-\mathrm{A} 2^{\mathrm{ii}}$ & $3.771(3)$ & $3.530(3)$ & $1.327(5)$ & $5.8(2)$ \\
\hline & $\mathrm{A} 1-\mathrm{A} 1^{\mathrm{iii}}$ & $3.515(2)$ & $3.280(3)$ & $1.265(5)$ & 0.0 \\
\hline 3 & $\mathrm{~B} 2-\mathrm{A} 1^{\text {iv }}$ & $3.871(2)$ & $3.683(3)$ & $1.191(6)$ & 19.2(1) \\
\hline 4 & - & - & - & - & - \\
\hline 5 & $\mathrm{~B} 2-\mathrm{B} 2^{\mathrm{v}}$ & $3.899(5)$ & $3.632(6)$ & $1.419(9)$ & $0.6(3)$ \\
\hline 6 & $\mathrm{~A} 2-\mathrm{A} 2^{\mathrm{vi}}$ & $3.916(3)$ & $3.654(4)$ & $1.408(6)$ & $4.4(2)$ \\
\hline 7 & $\mathrm{~A} 2-\mathrm{A} 2^{\mathrm{vii}}$ & $3.709(2)$ & 3.383(3) & $1.519(4)$ & 0.0 \\
\hline 8 & $\mathrm{~A} 2-\mathrm{A} 2^{\mathrm{viii}}$ & $3.710(2)$ & $3.379(2)$ & $1.531(3)$ & 0.0 \\
\hline
\end{tabular}

* C1: N1C to C5C; B2: C6B to C11B; D2: C6D to C11D; A2: C6A to C11A; A1: N1A to C5A.

Symmetry codes: (i) $3 / 2-x, y,-1 / 2+z$; (ii) $1-x, y, 1 / 2-z$; (iii) $1 / 2-x, 1 / 2-y,-z$; (iv) $x, 1 / 2-y, 1 / 2+z$; (v) $2-$ $x, 1-y, z ;(v i)-x,-y, z$; (vii) $-x,-y, 1-z$; (viii) 1/2-x, 1/2-y, 1-z. 


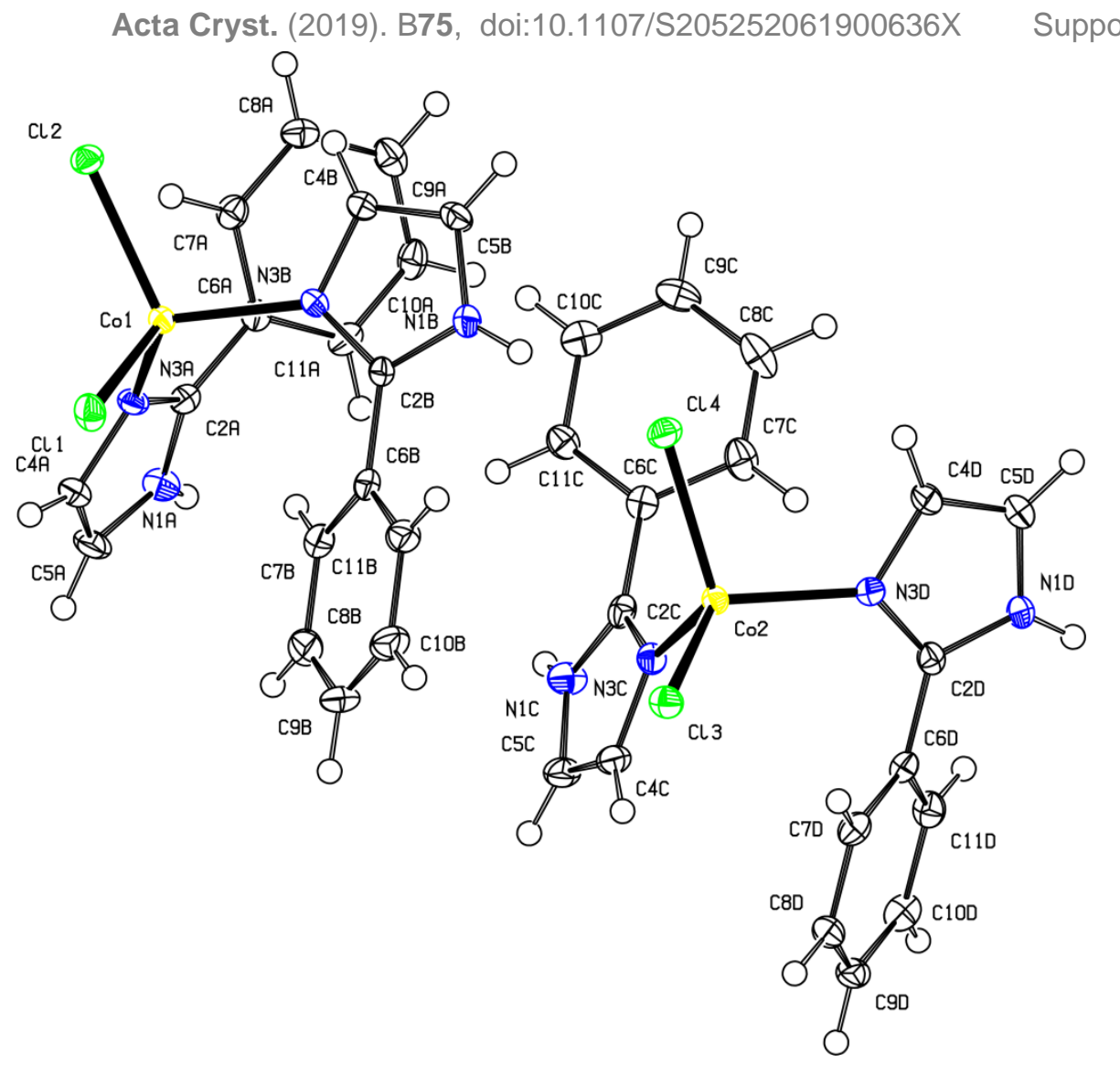

Figure S1 View of the asymmetric unit of compound 1 with atom labelling and displacement ellipsoids drawn at the $50 \%$ probability level.

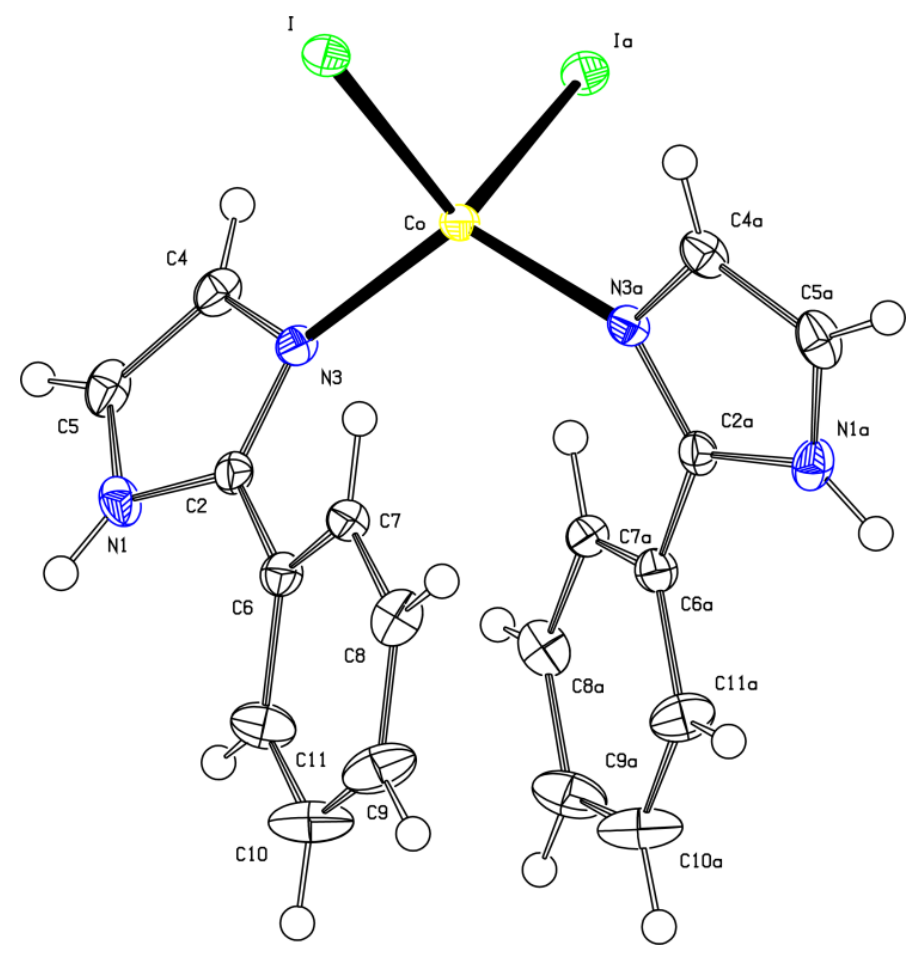

Figure S2 A view of the structure of compound $\mathbf{2}$ with atom labelling and displacement ellipsoids drawn at the $50 \%$ probability level. Symmetry code: (a) $1-x, y, 1 / 2-z$. 


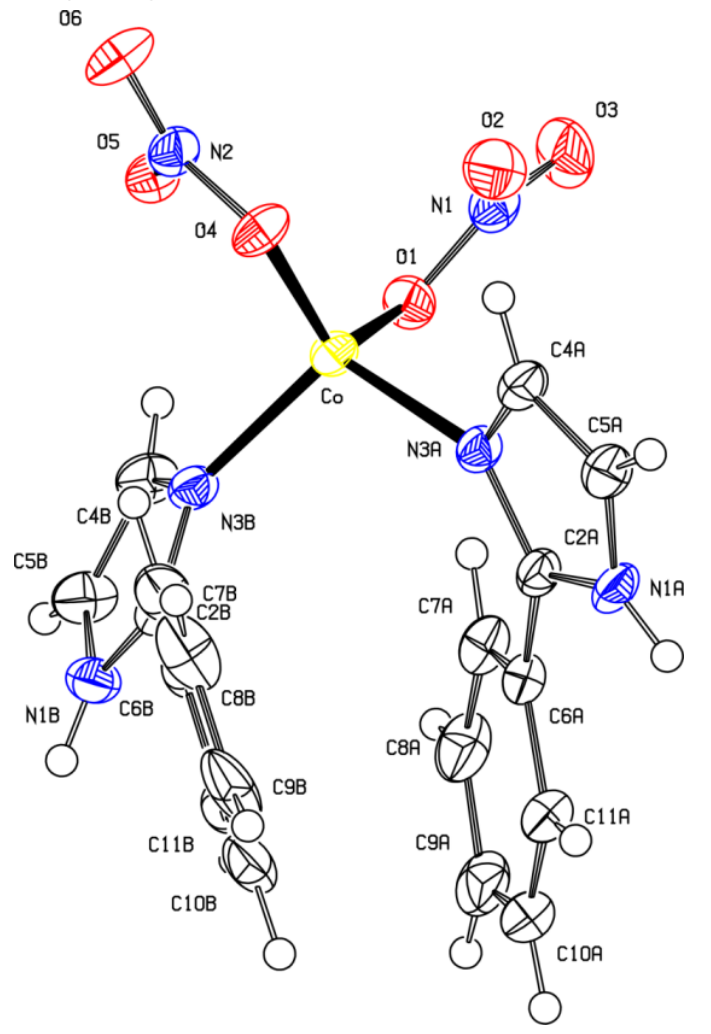

Figure S3 A view of the structure of compound $\mathbf{3}$ with atom labelling and displacement ellipsoids drawn at the $50 \%$ probability level.

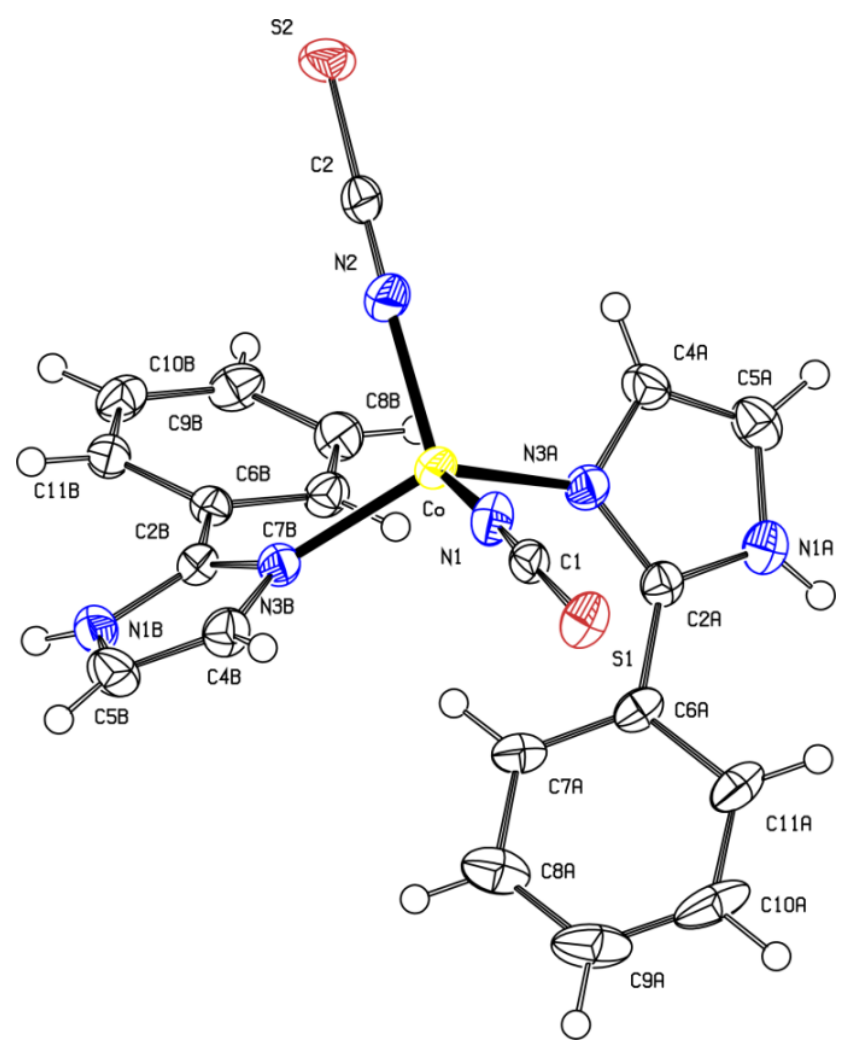

Figure S4 A view of the structure of compound $\mathbf{4}$ with atom labelling and displacement ellipsoids drawn at the $50 \%$ probability level. 


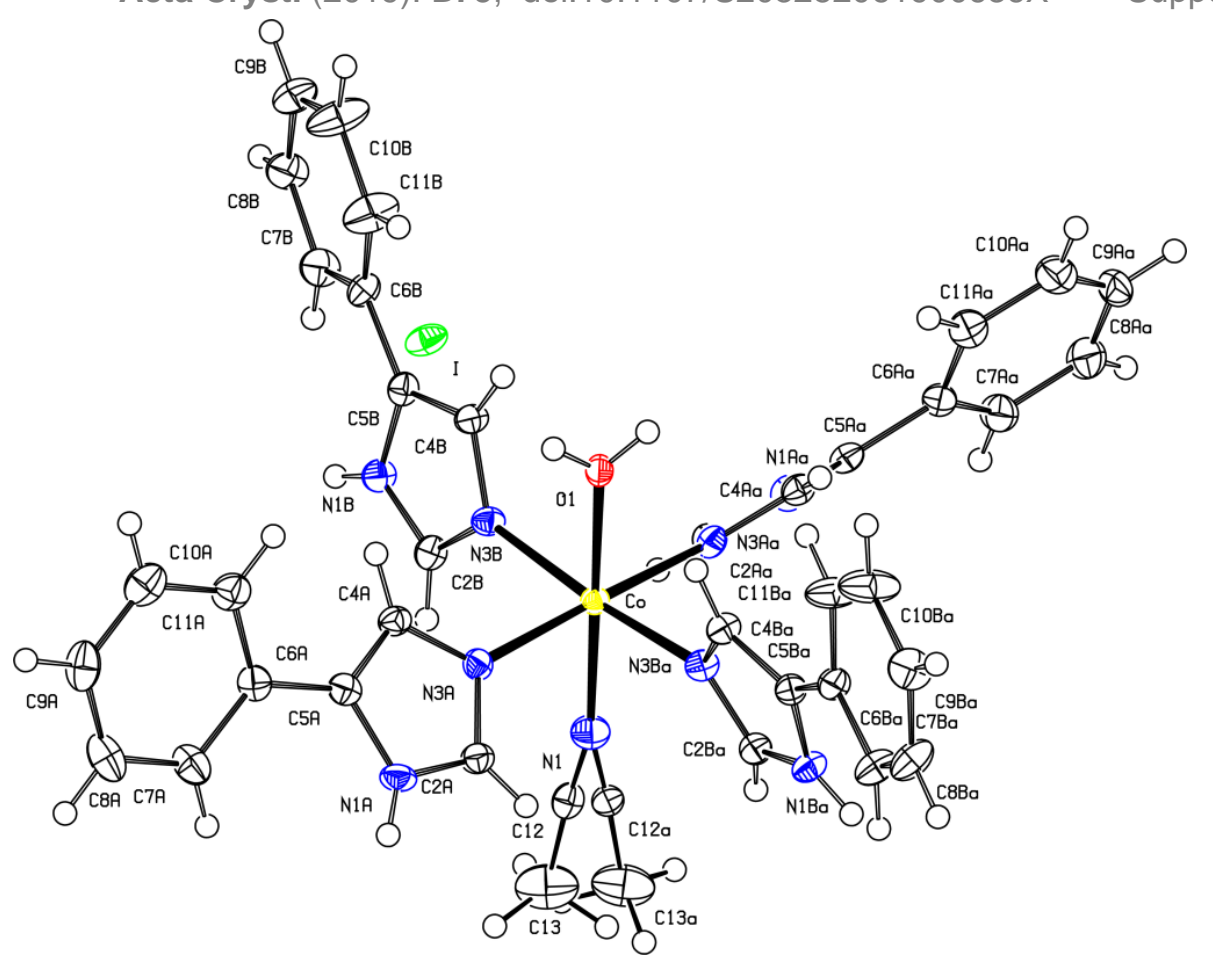

Figure S5 A view of the structure of compound 5 with atom labelling and displacement ellipsoids drawn at the 50\% probability level. Symmetry code: (a) $1-x, 1-y$, $z$. The disordered acetonitrile solvent molecule is shown with both orientations.

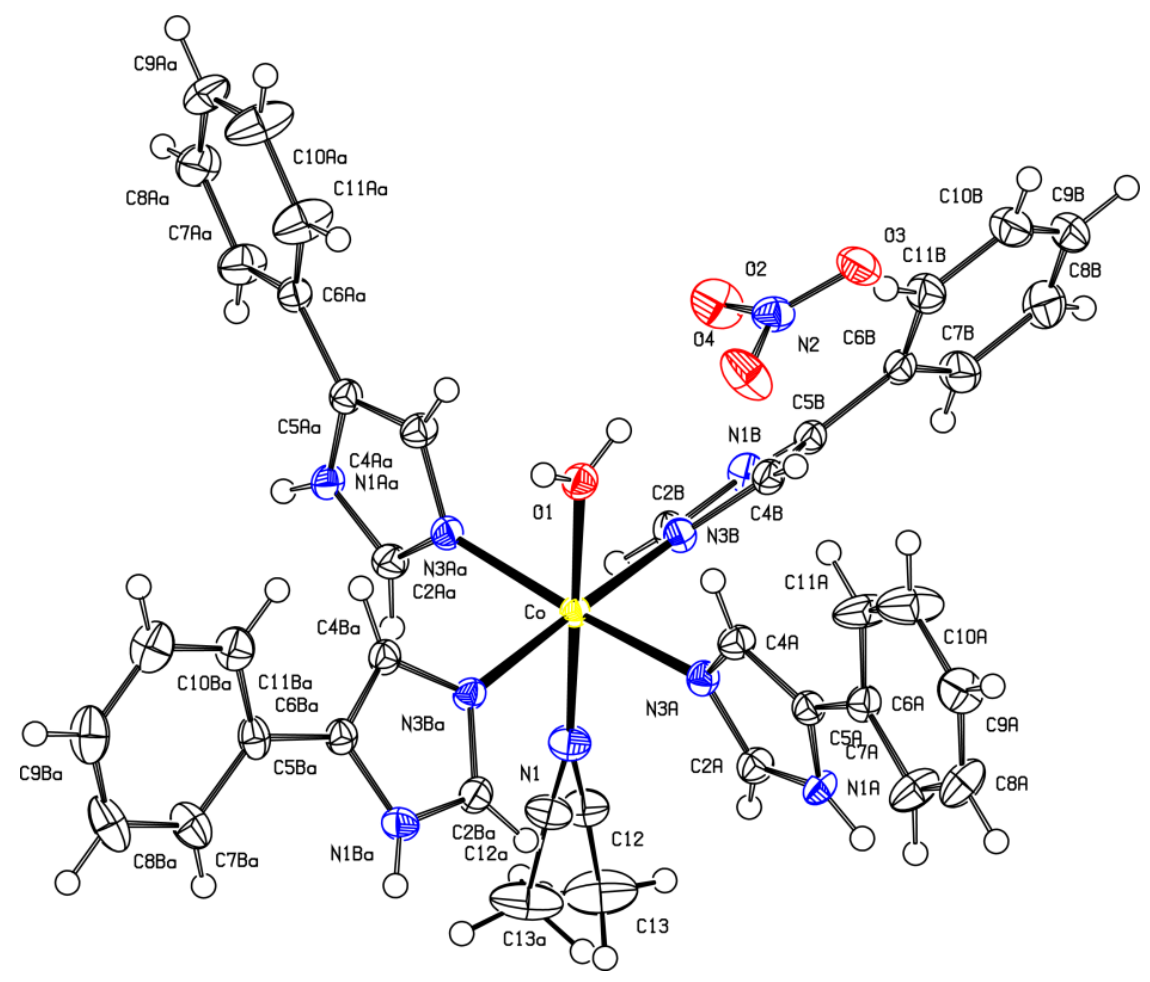

Figure S6 A view of the structure of compound $\mathbf{6}$ with atom labelling and displacement ellipsoids drawn at the 50\% probability level. Symmetry code: (a) $1-x,-y, z$. The disordered acetonitrile solvent molecule is shown with both orientations. 


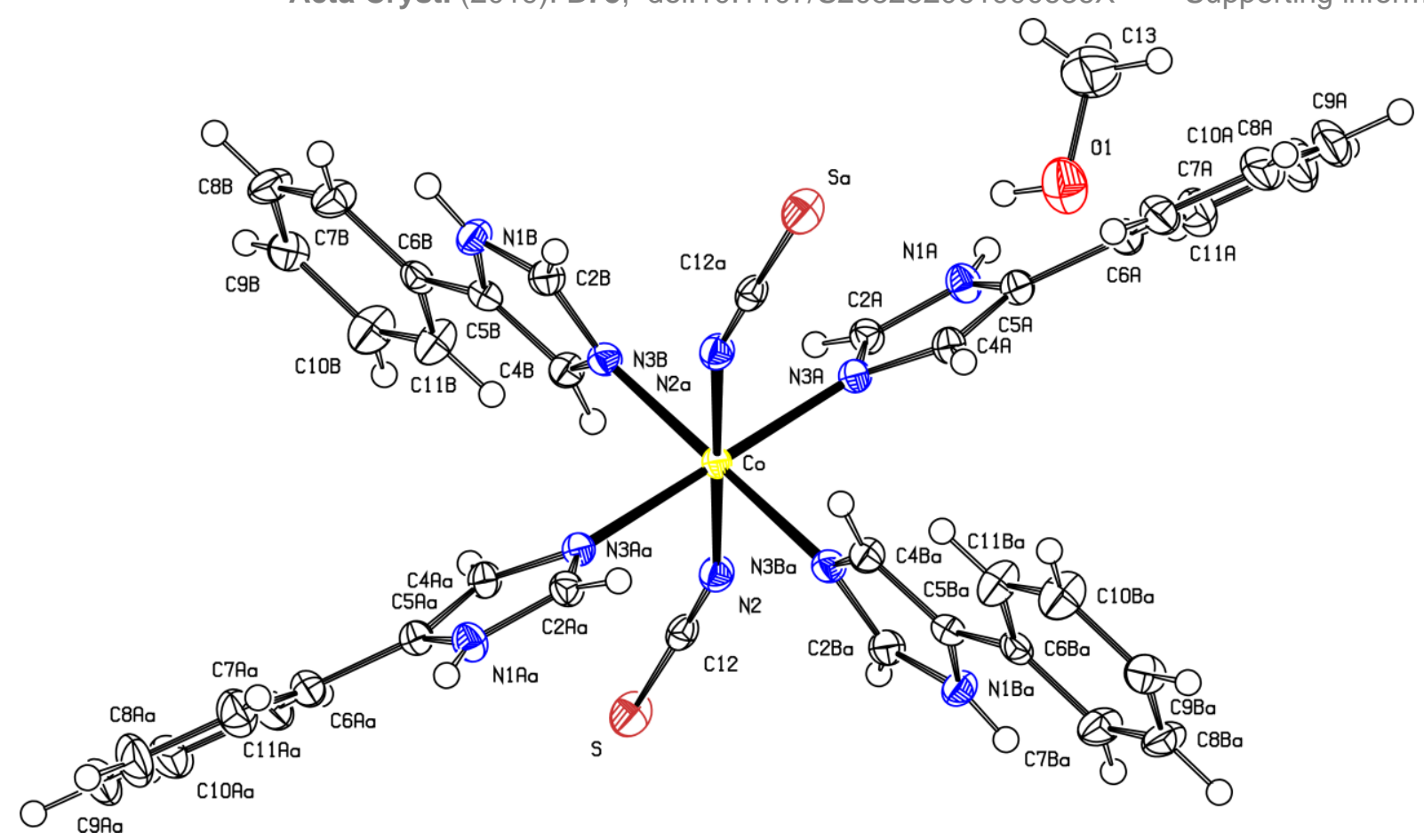

Figure S7 A view of the structure of compound 7 $\mathrm{MeOH}$ with atom labelling and displacement ellipsoids drawn at the 50\% probability level. Symmetry code: (a) $1-x,-y,-z$.

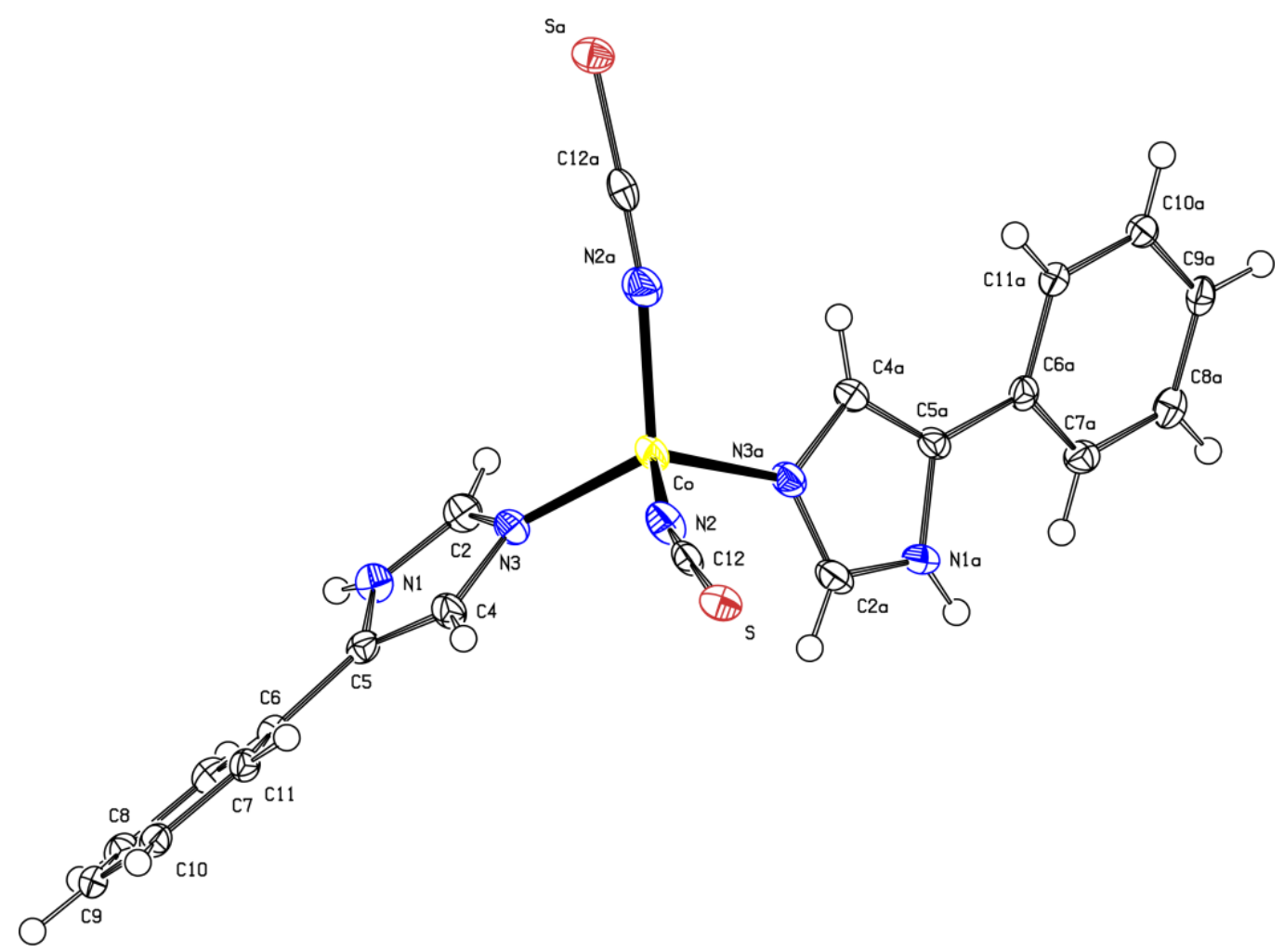

Figure S8 A view of the structure of compound 8 with atom labelling and displacement ellipsoids drawn at the $50 \%$ probability level. Symmetry code: (a) $1-x, y, 3 / 2-z$. 